\title{
Demência frontotemporal
}

André Barciela Veras ${ }^{1}$

Vanessa Ayrão ${ }^{2}$

Márcia Rozenthal ${ }^{3}$

Recebido: 24/9/2003 Aceito: 6/10/2003

RESUMO

Os autores descrevem um caso de demência frontotemporal e seu diagnóstico diferencial com outros tipos de demência. Unitermos: Demênciafrontotemporal.

ABSTRACT

Frontotemporal dementia

The authors describe a case of frontotemporal dementia establishing the differential diagnosis with other types of dementia.

Keywords: Frontotemporal dementia.

\section{Identificação}

C.C.M., sexo masculino, 58 anos, branco, casado, brasileiro, natural do Rio de Janeiro, residente em Niterói, agnóstico, terceiro grau completo, aposentado como economista da Secretaria de Fazenda.

\section{Queixa principal}

Não formula.

\section{Motivo da internação}

Heteroagressividade e alteração do comportamento.

\section{HDA}

Segundo relato da esposa, quando C. tinha 53 anos apresentou humor triste e anedonia, cerca de um ano após sua aposentadoria. Iniciou tratamento com medicação antidepressiva (venlafaxina), mas não sabe informar a dose. Quatro meses após o início do tratamento, apresentou agitação psicomotora, humor irritável e heteroagressividade, tendo sido internado no Hospital Pedro Ernesto (enfermaria de Psiquiatria). Recebeu então o diagnóstico de transtorno bipolar do humor e iniciou monoterapia com carbonato de lítio. Durante o ano em que usou essa medicação, alternava períodos de apatia e irritabilidade,

\footnotetext{
Instituto de Psiquiatria da UFRJ - IPUB.

Presidente.

Integrante do Programa de Psiquiatria Infantil no IPUB - setor do GEDA.

Médica Assistente.

Endereço para correspondência:

André Barciela Veras

Rua Jequitibá, 1, ap. 502, bl. 2

Rio de Janeiro, RJ - CEP 22470-110

E-mail: barciela@ibest.com.br
} 
acrescentando a essa sintomatologia mussitação e atitude alucinatória. Foi procurado outro psiquiatra que suspeitou tratar-se de doença degenerativa e solicitou tomografia de crânio, sorologia para HIV, dosagem de TSH, T4 livre, vitamina B12, folato e sorologia para lues. Todos os exames encontravam-se normais (sic). O comportamento do paciente foi progressivamente se agravando, apresentando perseveração do pensamento e jocosidade. Tornou-se agressivo com esposa e filho, não aceitava abordagem de pessoas desconhecidas e tentou agredir a empregada sem motivo aparente. A conduta do psiquiatra foi suspender o carbonato de lítio e iniciar tentativas com antipsicóticos atípicos - recebeu então o diagnóstico de "doença corpuscular de Lewy".

Aos 55 anos, realizou uma ressonância nuclear magnética que revelou proeminência de sulcos corticais na região frontal. Começou a apresentar esquecimento de fatos recentes e piora dos sintomas já descritos.

Em novembro de 2001, aos 56 anos, C. saiu de casa para comprar cigarros e ficou perdido por 24 horas, sendo encontrado pela família próximo à sua residência. Apresentava diversas escoriações pelo corpo e edema no cotovelo direito, sendo levado ao ortopedista. Durante a consulta, impulsivamente agrediu o médico. A família o levou então ao Instituto Philipe Pinel, sendo posteriormente transferido para o IPUB em 21/11/2001.

\section{História patológica pregressa}

O paciente apresentou doenças comuns da infância (varicela, sarampo). Nega patologias crônicas (hipertensão arterial, diabetes melito, cardiopatias, doença renal e/ou hepática). Nega também alergias, transfusões sangüíneas e cirurgias, além de DSTs.

\section{História fisiológica}

Nascido de parto vaginal a termo, sem intercorrências. A família nega alterações de desenvolvimento psicomotor.

\section{História familiar}

Tia paterna faleceu aos 56 anos internada em hospital psiquiátrico, segundo familiares com quadro semelhante. Não fornecem maiores informações.

Pai e mãe falecidos, a família não sabe informar a causa.

Irmã com transtorno depressivo maior, no momento em remissão.

\section{História pessoal}

C. é o mais velho de uma prole de três. Completou o terceiro grau e trabalha desde os 18 anos.
Começou a namorar M. (sua atual esposa) na idade de 17 anos e casaram-se aos 20 anos, enquanto ainda cursavam juntos a faculdade. A esposa diz que C. sempre foi um excelente profissional. Participava ativamente do partido político da sua cidade. Tiveram um filho, hoje com 30 anos.

Mora com a esposa e o filho em Niterói. Após o início da doença, seus contatos sociais foram diminuindo progressivamente.

A família nega abuso de álcool ou drogas. Fuma cerca de dois maços e meio de cigarros por dia.

\section{Exame físico}

\section{Sinais vitais: PA $130 \times 80 \mathrm{mmHg} \quad$ FC $87 \mathrm{bpm}$ FR 19 rpm \\ Tax 36,3}

Somatoscopia: paciente apresentando-se emagrecido; normocorado, anictérico, acianótico, normohidratado, eupnéico, apirético e sem linfonodomegalias. Apresenta extremidades distais de segundo e terceiro quirodáctilos direitos escurecidas pelo hábito de fumar, além de algumas queimaduras leves na mesma região.

ACV: RCR em 2T; BNF, sem sopros.

AR: MVUA sem ruídos adventícios.

Abdome: indolor à palpação superficial e profunda, ausência de visceromegalias.

\section{Exame neurológico}

Marcha atípica; tônus e força muscular preservados.

Reflexos osteotendíneos sem alterações. Reflexo palmomentoniano presente bilateralmente. Reflexo orbicular da boca exacerbado. Reflexo cutaneoplantar em flexão bilateralmente.

Ausência de sinais extrapiramidais.

Nervos cranianos sem alterações.

Não apresenta sinais de irritação meníngea, alterações esfincterianas ou tremor de extremidades.

Miniexame do estado mental:

- dezembro de 2001 - escore de 21/30;

- 25 de março de 2002 - escore de 13/30;

- março de 2003 - não coopera.

\section{Exame psíquico}

Encontramos o paciente no pátio interno da enfermaria masculina trajando vestes fornecidas pela instituição, que se encontram sujas de cinza de cigarro e desalinhadas. Encontra-se descalço e em condições precárias de higiene. Ele se dirige ao posto de enfermagem, onde pede por cigarro de forma perseverante. 
Ao abordá-lo e solicitar que nos acompanhe para um outro recinto a fim de realizar uma entrevista, o paciente apenas desvia o olhar em minha direção e continua pedindo um "cigarrinho". C. me acompanha inicialmente sem resistência ao ser conduzido pela mão, mas durante o percurso tenta voltar à enfermaria diversas vezes. Essa resistência é facilmente vencida com a insistência de que me acompanhe ou com a promessa de lhe dar um cigarro.

Ao chegar na sala de exame, o paciente senta-se imediatamente no local indicado. C. permanece com os cotovelos apoiados sobre os joelhos e o olhar fixo em uma das pessoas que se encontrava à sua frente na sala. Quando chamado, só desvia o olhar após várias tentativas. Responde corretamente seu nome, mas, em relação às demais perguntas, ou não responde ou o faz de forma breve e pouco compreensível. Diversas vezes levanta em direção à porta, voltando a se sentar quando interpelado. As etapas do miniexame do estado mental tornam-se inexeqüíveis pela atenção praticamente inexistente ao exame. Na última vez que o paciente se levanta para deixar a sala apenas o observamos, C. abre a porta e volta calado para a enfermaria.

\section{Súmula psicopatológica}

Aparência: descuidada.

Atitude: indiferente e negativista.

Fala e linguagem: não-fluente, perseverante; ecolalia.

Consciência: sem rebaixamento do nível de consciência.

Orientação: desorientação cronopsíquica, desorientação espacial parcial; orientado autopsiquicamente.

Consciência do eu: sem alterações ao exame.

Atenção: hipotenaz e hipovigil.

Pensamentos: curso: alentecido;

forma: perseverante;

conteúdo: empobrecido.

Sensopercepção: sem alterações.

Humor: eutímico.

Afeto: embotado.

Volição: hipobúlico.

Pragmatismo: hipopragmático.

Memória: perda das recordações tardias e da capacidade de fixação.

Inteligência: abaixo do grau de escolaridade.

Psicomotricidade: empobrecida.

Consciência de morbidade: ausente.

Planos para o futuro: não formula.

\section{Diagnóstico sindrômico}

Síndrome demencial.

\section{Diagnóstico nosológico}

Eixo I Episódio depressivo.

Eixo II Empobrecimento intelectual progressivo.

Eixo III Demência frontotemporal (F03 da CID-10).

Eixo IV Início da aposentadoria coincidente com o início do quadro.

Eixo V Dependência de cuidadores para realização de atividades básicas.

\section{Diagnóstico diferencial}

Demência na doença de Pick (F02.0 - CID-10).

Demência na doença de Alzheimer (F00 - CID-10).

Demência na doença vascular (F01 - CID-10).

\section{Evolução}

\section{Dezembro de 2001}

O paciente estava bastante agressivo no início da internação; era difícil a abordagem e a equipe de saúde tinha receio de sua agressividade. Em alguns momentos, recusava-se a tomar a medicação oral. Quando abordado, esquivava-se ou tinha atitude ameaçadora, chegando a agredir algumas vezes a equipe de enfermagem. Apresentava também insônia. Foi iniciado tratamento com trazodona $(25 \mathrm{mg} / \mathrm{dia})$, com melhora importante da agressividade e da insônia. Como o paciente apresentava mussitação, alucinação auditiva e negativismo, foram introduzidos olanzapina $10 \mathrm{mg} / \mathrm{dia}$ e lorazepam $6 \mathrm{mg} / \mathrm{dia}$. Após 3 semanas, ainda apresentava mussitação e alucinação auditiva; a olanzapina foi então substituída por risperidona $3 \mathrm{mg} /$ dia, com boa resposta.

\section{Março de 2003}

O paciente permanece no leito durante quase o dia todo. Levanta-se apenas para fumar e se alimentar. Não cuida espontaneamente de sua higiene pessoal. Não tem apresentado mais episódios de agressividade, mussitação ou alucinações auditivas. Permanece em uso de $25 \mathrm{mg} /$ dia de trazodona e $2 \mathrm{mg} /$ dia de risperidona.

Recebeu alta em abril do mesmo ano, com seguimento em regime ambulatorial. 
Exames laboratoriais relevantes

Transcrição do laudo da RNM de crânio com espectroscopia realizada em 20/2/2002, no Hospital Barra D'or:

"Sulcos corticais e fissuras laterais marcados, especialmente nos lobos frontais".

"Foco de sinal elevado em T2 e Flair observados na substância branca periventricular, nas coroas radiadas, nos centros semiovais e subcortical frontal à direita".

"Sistema ventricular dentro dos limites anatômic os".

"Redução significativa dos níveis relativos do NAA compatível com diminuição da densidade neuronal cortical".
"Esses achados sugerem possibilidade de processo neurodegenerativo cortical".

Transcrição do laudo da RM de crânio com espectroscopia realizada em 11/3/2003, no IRM, Humaitá:

"Microangiopatia degenerativa da substância branca, inalterado em comparação com o exame realizado em 28/3/2001".

"Hipocampos com volume normal".

"Importantes alterações espectrais na margem posterior do giro do cíngulo".

"Redução do número e viabilidade neuronal frontal associado ao aumento dos níveis de glutamina e glutamato nesta topografia." 